\title{
A QUESTÃO DO NARRADOR E AS DUAS INSUSTENTÁVEIS LEVEZAS DO SER: NO ROMANCE E NO FILME
}

\author{
Wilton Barroso FILHO ${ }^{1}$ \\ Programa de Pós-graduação em Teoria Literária da UNB \\ wbf@unb.br \\ Maria Veralice BARROSO ${ }^{2}$ \\ Programa de Pós-graduação em Teoria Literária da UNB \\ mariaveralice@ig.com.bt \\ Itamar Rodrigues PAULINO \\ Universidade Federal do Oeste do Pará \\ itasophos@gmail.com
}

Resumo: O filme A Insustentável Leveza do Ser é uma adaptação do romance de Milan Kundera, publicado nos anos finais do século passado. O presente artigo tem por objetivo procurar compreender a relação estabelecida entre o original e a tradução proposta pelo diretor Philip Kaufman. No exercício de decomposição e análise das duas obras buscar-se-á, pelos momentos em que a ausência do narradorautor provoca no leitor-espectador certa reação diante da produção cinematográfica.

Palavras-chave: Narrador. Autor. Voz filosófica.

Abstract: The movie The Unbearable Lightness of Being is an adaptation of Milan Kundera romance which was published by the end oflast Century. This article has an aim of getting some understanding about the established relation between the original book and its translation into a movie by the director Philip Kaufman. We have the proposal of searching the moments of narrator-author absence that provoke some reaction of the lector-spectator before the cinematographic production. The way to reach the aim of this article is by the exercise of decomposing and analyzing both masterpieces: the book and the movie.

Keywords: Narrator. Author. Philosophical voice.

\footnotetext{
${ }^{1}$ Wilton Barroso Filho é Professor Doutor em Filosofia pela Universidade de Paris VII. Titular do Programa de Pós-graduação em Teoria Literária da Universidade de Brasília - PPGL - UnB, Brasil.

${ }^{2}$ Maria Veralice Barroso é Mestre e doutoranda em Teoria Literária pela Universidade de Brasília - UnB, Brasil.

${ }^{3}$ Itamar Rodrigues Paulino é Mestre em Filosofia e Doutorando em Teoria Literária pela Universidade de Brasília - UnB, Brasil. Professor da Universidade Federal do Oeste do Pará - UFOPA, Brasil.
} 
Uma parcela significativa das melhores produções cinematográficas deve ser pensada na relação de seus autores com a literatura. Do interior dessa perspectiva relacional deparamos-nos com o filme produzido na década de 80 por Saul Zaentz e dirigido por Philip Kaufman, com roteiro de Jean-Claude Carrière: A Insustentável Leveza do Ser.

Este filme é o resultado da adaptação de um romance importante do final do século XX, o texto de mesmo nome publicado também na década de 80 pelo romancista tcheco Milan Kundera. Assim como o livro, e, provavelmente, influenciado pelo sucesso dele, o filme de Kaufman teve grande repercussão junto ao público e junto à crítica, o que lhe rendeu em 1988 duas indicações ao Oscar: o de melhor roteiro adaptado e o de melhor fotografia.

Chama atenção do pesquisador o fato de que, muito embora, a adaptação de Kaufman tenha resultado numa bela obra, legitimada pela crítica cinematográfica, confirmada pelos espectadores - especialmente os leitores do romance. Ao visitarmos os sites da internet sobre o filme, a aproximação da adaptação com o original é inevitável na voz dos comentadores, sendo controlada fundamentalmente por uma relação de hierarquia. Nessa relação, os espectadores-leitores geralmente reconhecem a beleza do filme e o fato de que ele e o romance são obras diferentes, mas ainda assim insistem na supremacia do texto literário.

O filme abandona, contudo, algumas das mais profundas reflexões de carácter existencial. Apesar de esta dimensão não ter sido completamente subtraída ao texto original, a adaptação cinematográfica é incapaz de captar a verdadeira essência do título da obra que afinal caracteriza cada uma das personagens. Mas ainda assim é pela beleza do(s) argumento(s) que o filme nos encanta e nos comove. ${ }^{4}$

O filme tem uma bela fotografia. Não resta dúvida. Talvez eu desse 5 estrelas se não tivesse lido o livro. Mas, eu li. Não entrei de inocente. Eu já estava contaminado pela riqueza do texto de Kundera. ${ }^{5}$

\footnotetext{
${ }^{4}$ http://www.urbi.pt/000418/cultura/filme.html

${ }^{5}$ http://claudioalex.multiply.com/journal/item/797/797
} 
As declarações chamam ainda mais atenção se atentarmos para o fato de que os trechos acima são partes de julgamentos cuja íntegra revela certa autoridade de quem os profere. Não é de uma fidelidade para com o texto literário no sentido de imitá-lo, como geralmente se observa no senso comum, que essas pessoas sentem falta, do que elas ressentem, e cobram da adaptação de Kaufamn, é a suposta ausência do teor reflexivo contido no original. Sendo assim, a pergunta que se impõe é: o que faz o filme de Kaufman deixar diante do leitor a sensação de falta, levandoo (leitor) a persistir na proposição segundo a qual o filme não traduz o espírito do original?

Conscientes de que uma postura no sentido de rejeitar simplesmente a aproximação desigual empreendendo uma defesa em favor do caráter autônomo do filme, por si só, não contribuiria com a discussão nem tão pouco seria suficiente para minimizá-la, a nossa proposta se encaminha então no sentido de ir em busca de fundamentos, de elementos capazes de fornecer uma compreensão, menos opinativa e mais metodológica, a respeito das causas mais prováveis dessa relação que, de certa forma, parece ter se cristalizado na concepção dos espectadores-leitores.

\section{$1 \mathrm{O}$ problema do narrador}

Ao decompor o romance em busca de regularidades, de procedimentos formais que nos levem a fundamentos epistemológicos ${ }^{6}$ capazes de remeterem à pergunta kantiana "O que eu posso saber?" (BARROSO, 2003), deparamo-nos com um elemento de destaque na narrativa kunderiana e que talvez ilumine a discussão: aquele que diz respeito à voz filosófica do narrador (BARROSO, 2008). Dentre vários, esse é um elemento que, se não tocado pela tradução, figuraria certamente na sensação de incompletude dela ou, nesse caso, poderia ferir, ao menos na concepção dos leitores do romance, aquilo que Bazin chamou de princípio, de essência da obra (BAZIN, 1991, p. 95-96).

\footnotetext{
${ }^{6}$ Existe uma tendência na pesquisa especializada em usar a epistemologia, nas mais diversas aéreas do conhecimento. Ver, Revista Cerrados/ publicação do Departamento de Teoria Literária e Literaturas, Org. Sylvia Helena Cyntrão; ano 15, n. 21 (2006). UnB, Brasília, 2006, p. 123
} 
Desde muito cedo Kundera demonstrou-se preocupado com a posição do narrador na constituição de sua criação estética. Já em $A$ brincadeira (1967) romance de estreia no gênero, ele apresenta ao mundo romanesco uma espécie de narrador coletivo que se caracteriza, sobretudo, pela condução da narrativa na voz de quatro personagens as quais narram em primeira pessoa.

O zelo quando o assunto é a construção do narrador, evolui significativamente no curso da obra a ponto de o escritor não mais se contentar com a simples condição de organizador das consciências no grande diálogo. Não admitindo permanecer do lado de fora da narrativa, Kundera cria um espaço para si dentro dela e, ao se corporificar, manifesta-se diante do leitor enquanto autor, narrador e personagem simultaneamente, criando um modelo de narrador singular para o desenvolvimento de sua atividade literária. Basta lembrar o grande adeus do autor, ao leitor e aos seus personagens, no final de $A$ Imortalidade (1990).

Essa categoria complexa de narrador adotada por Kundera é carregada de intenções e significações. Ela se constitui em variações do romance que permite ao autor realizar e credibilizar de modo mais expressivo as reflexões empreendidas pela voz do narrador sobre o homem e suas relações consigo mesmo, com os outros e com o mundo onde vive suas experiências e, simultaneamente, compõe o quadro da 'pequena história', ou seja, da história individual cotidianamente vivenciada, esta por sua vez se entrelaça à 'Grande' História, aquela compreendida pela história oficial ou factual'. É nesse contexto narrativo, portanto, que deparamonos com A Insustentável Leveza do Ser.

$\mathrm{Na}$ Insustentável Leveza do Ser, a voz filosófica do narrador personificase na voz do autor quando este descreve o momento exato do nascimento de Tomas.

\footnotetext{
${ }^{7}$ Existe hoje uma tendência dos historiadores, especialmente aqueles voltados para os estudos culturais, em tomar as experiências do cotidiano como fonte de estudos. Embora numa perspectiva menos cultural e mais literário-filosófica, Kundera parece compartilhar do desejo de compreender a história não tanto por meio dos atos grandiosos, dos feitos dos grandes heróis, mas sim por meio das experiências cotidianamente vivenciadas pelos homens comuns. Tal desejo se evidencia quando nos diz que "não apenas a circunstância histórica deve criar uma nova situação existencial para um personagem do romance, mas a História deve em si mesma ser compreendida e analisada como situação existencial (1988, p. 38).
} 
Há muitos anos penso em Tomas. Mas é sob a luz dessas reflexões que o vi claramente pela primeira vez. Eu o vejo de pé, numa das janelas de seu apartamento, os olhos fixos, do outro lado do pátio, na parede do prédio defronte, sem saber o que fazer (KUNDERA, 1995, p. 12).

Aqui, compartilhamos com o narrador-autor o momento sublime da criação em que Tomas deixa de pertencer ao universo da consciência do criador e passa a agir no mundo concreto da vida, enquanto outra consciência, aquela que se constrói gradativamente como um todo, mediada pelo processo de experimentação das possibilidades do indivíduo. Numa certa medida, o narrador-autor procede a uma criação literária de forte inspiração kantiana (sublime), mas ao se transformar durante este processo atinge uma prática transformadora de inspiração hegeliana, tal como ensinou Luckács (2000).

Como bem confidencia o narrador-autor, Tomas nasce sob à luz do pensar filosófico a respeito do mito nietzscheano do Eterno Retorno e das discussões acerca dos pólos contrários de Parmênides, especialmente o peso e a leveza, que segundo ele (narrador-autor), constitui-se na mais misteriosa e ambígua de todas as contradições. Sendo resultado dessas reflexões asseguradas pela vozfilosófica do narrador com a autoridade de autor, Tomas e as demais personagens com as quais se relaciona, especialmente Tereza e Sabina, não podem ser desvinculadas seja do incômodo Eterno Retorno nietzscheano, seja das contradições de Parmênides, pois segundo a voz do narrador, que se manifesta com autoridade de autor, são esses os fundamentos que os geram, são eles que irão conduzi-los no interior do romance.

Com Tereza e Sabina, Tomas vive um triângulo amoroso onde o peso do amor de Tereza se contrapõe à leveza existencial de Sabina, tais relações são representativas de uma busca de Tomas não pelo outro, mas por si mesmo, pelo equilíbrio entre os pólos negativos e positivos de Parmênides. Contudo, essa busca pelo equilíbrio pressupõe a difícil tarefa de efetuar escolhas e, para Tomas, segundo o narrador,

Não existe meio de verificar qual é a boa decisão, pois não existe termo de comparação. Tudo é vivido pela primeira vez e sem reparação. Como se um ator 
entrasse em cena sem nunca ter ensaiado. Mas o que pode valer a vida, se o primeiro ensaio da vida já é a própria vida? (KUNDERA, 1995, p. 14).

A consciência quanto às incertezas ou a impossibilidade mesmo de retornar faz a vida ser tratada como um esboço onde cada momento deve ser vivido e experimentado como único, pois num mundo fundado pela inexistência do retorno, tudo estará perdido tão logo seja vivido8 .

A busca pelo equilíbrio confrontada com a identificação com provérbio alemão einmal ist keinmal, uma vez não conta, desse modo, uma vez é nunca, se por um lado, faz de Tomas um sedutor kunderiano voraz e frenético, por outro, exige do autor uma estética literária capaz de driblar a condição imposta pela inexistência do retorno. É desse modo então, que estrategicamente o autor cria uma estrutura narrativa onde seja possível, uma mesma situação tornar-se cíclica como afirmou Nietzsche, e poder ser vivida várias vezes, circularmente, por diferentes personagens. A repetição dos acontecimentos e a variedade de suas vivências permitem à voz filosófica do narrador uma inserção mais aprofundada frente às ações e às reações das personagens que de modo variado nas suas vivências, experimentam as diversas possibilidades humanas.

Tal qual Tomas, as demais personagens de $A$ Insustentável Leveza do Ser pertencem à categoria denominada por Kundera de 'ego experimental'. Para o autor a personagem dentro dessa perspectiva está para além da simulação de um ser vivo, ela nasce para testar e experimentar as reflexões propostas pela voz do narrador autoral acerca das possibilidades humanas e suas contradições na trajetória da 'pequena e da Grande História'. Desse modo, é a partir do relacionamento amoroso entre Sabina e Franz - no qual Franz em relação à Sabina é a representação do peso e da nostalgia contidos no intelectual do final do século XX - que tem sobre os ombros o seguinte paradoxo terminal, de um lado, o recurso ao princípio intransigente da racionalidade moderna, do outro, o mundo das relativizações. O vazio

\footnotetext{
${ }^{8}$ Daí percebermos, numa perspectiva heraclitiana, que uma oportunidade perdida, estaria perdida para todo o sempre. O pensamento filosófico de Heráclito diz respeito ao Ser que é e vem-a-ser, um Ser em permanente mudança (devir); enquanto que Parmênides, citado pelo próprio narrador kunderiano, defende a ideia do Ser que É e do não-Ser que não é.
} 
deixado pelos conflitos bélicos que promoveram as duas grandes guerras mundiais e a divisão do mundo em dois blocos, o socialista e o capitalista - que o narrador ao mesmo tempo em que nos coloca frente aos conflitos existenciais do homem que cada vez mais se fragmenta e caminha para vazio existencial no curso da história, nos conduz a uma reflexão, junto com ele, sobre a condição humana dentro dos paradoxos terminais do mundo moderno.

O gesto filosófico do narrador que compartilha com o leitor acerca das experiências humanas no crepúsculo da modernidade se confirma na voz do autor quando este, num de seus ensaios, afirma que,

Depois de ter conseguido milagres nas ciências e na técnica, este 'senhor e dono' se dá conta subitamente de que não possui nada e não é senhor nem da natureza (ela se retira, pouco a pouco, do planeta) nem da História (ela lhe escapou) nem de si mesmo (ele é guiado pelas forças irracionais de sua alma). Mas se Deus foi embora e o homem não é mais senhor, quem então é senhor? O planeta caminha no vazio sem nenhum senhor. Eis a insustentável Leveza do ser. (KUNDERA, 1988, p. 41).

Pensando nas palavras de Kundera e no momento histórico em que ele está situado quando profere tal afirmação remetemo-nos a Eric Hobsbawm, mais especificamente a seu livro Era dos extremos: o breve século $X X$, quando do ponto de vista histórico assegura que "não há como duvidar seriamente de que em fins da década de 1980 e início da década de 1990 uma era se encerrou e outra nova começou." E ainda que, "À medida que a década de 1980 dava lugar à de 1990, o estado de espírito dos que refletiam sobre o passado e o futuro do século era de crescente melancolia fin-de-siècle" (HOBSBAWM, 1995, p. 15-16).

Tais observações nos fazem crer que a voz filosófica remete o leitor ao lugar de fala do narrador-autor enquanto sujeito da história, tornando mais críveis as reflexões por ele empreendidas. Dessa maneira, a tríade narrador-autor-personagem, no romance, estabelece com o leitor um contrato de leitura pautado na confiança, na credibilidade do que é dito. Essa relação assegura ao leitor uma noção de verdade que vai além da verdade ficcional, cria-se uma espécie de realidade ficcional em que o 
leitor sente-se à vontade para deixar de ser simples observador e passa à condição de participante e sujeito da narrativa, torna-se um co-construtor das reflexões coordenadas pela voz filosófica do narrador-autor.

O tipo de narrador de A Insustentável Leveza do Ser pertence ao mundo do romance, é um aspecto técnico da moderna narrativa polifônica que permite o uso de até três pessoas (eu, ele, a gente) a um mesmo narrador. São vozes, onde uma delas é hegemônica, e assume a atitude de "intercambiar experiências" (BENJAMIN, 1994), podemos chamar essa voz principal de a voz do autor. Esses múltiplos aspectos contidos em um mesmo narrador, coloca em um mesmo plano uma estrutura nova que comporta o narrador, o autor e as personagens. Essa característica complexa constitui-se na principal característica do narrador do romance do século XX. As personagens são produtos romanescos da dialética existente entre o narrador e o autor. Conflito ou convergência, pouco importa, há nessa técnica a possibilidade nova de intercâmbio de experiências com o leitor. $O$ autor que se esforçava desde Flaubert para estar ausente, retoma, ao longo do século XX, um novo papel, o de dar um valor novo à narrativa, não basta apenas ser verossímel, tem que ser crível, ter credibilidade.

Um olhar atento do conjunto da obra romanesca de Milan Kundera revela uma busca evidente por esse narrador polifônico e complexo. Mas sua narrativa é original por que busca dar à voz do autor uma característica reflexiva, profunda, que nos faz pensar em uma vozfilosófica. Gerando uma nova tríade do ponto de vista da recepção: o leitor, o autor, o narrador. A cumplicidade implícita entre o narrador, o autor e o leitor, a dificulta a aceitação identitária de qualquer leitura de $A$ Insustentável Leveza do Ser que prescinda da figura do narrador.

"Praga, em 1968, vivia um jovem médico chamado Tomas..." [...] "Mas a mulher que mais o compreendia era Sabina." [...] "Tomas foi enviado a um spa para realizar uma operação"[...] Emitidas por um narrador figurativo, são exatamente essas as frases que dão início à narrativa cinematográfica de $A$ Insustentável leveza do Ser. Os três períodos configuram-se em três momentos singulares no filme, já que se constituem nos únicos em que o diretor se utiliza da voz do narrador. Nesses restritos espaços, a abordagem do narrador se apresenta desprovida de qualquer elemento que revele a intenção de fazer o espectador a ela se 
apegar enquanto fundamento epistemológico relevante quando se trata da decomposição e compreensão da obra, em verdade, na maioria das vezes, o narrador passa despercebido por quem assiste ao filme.

Do modo como está posta, a voz do narrador tem aqui um valor mais estético do que semântico, pois em se tratando da interpretação dos sentidos é perfeitamente possível abrir mão desse recurso na atividade hermenêutica. O que equivale a dizer que no filme de Kaufman, nos parcos momentos em que se faz presente, o narrador ocupa um lugar figurativo e, em vez de atribuir maior complexidade ao texto como o faz no romance, torna a narrativa mais clara, menos dúbia. Literalmente ele abre as cortinas e revela diante do espectador o sedutor insaciável representado por Tomas e os conflitos ${ }^{9}$ entre o amor e o sexo por ele vividos os quais evoluem para uma história de amor vivida com Tereza, história essa que acaba constituindo-se em tema central da narrativa. Nesse sentido, percebemos nessas pequenas manifestações, que o narrador construído por Kaufman cumpre um papel bem diferente daquela centralidade e densidade que lhe é conferida no romance kunderiano. Para esse sedutor, o sexo deixa de ser uma prática de si (FOUCAULT, 2006) ${ }^{10}$ passando a configurar como o prazer pela aventura pura e simples.

Muito provavelmente, Kaufman não ignorava a centralidade da figura do narrador no texto de Milan Kundera quando de sua adoção como referência para a produção cinematográfica, mesmo assim, no processo de tradução, optou pela ausência da voz filosófica dele no filme. Por que o diretor abdicou da figura do narrador? Esta é uma pergunta para a qual não temos resposta. O que podemos dar conta é da decomposição do filme no sentido de procurar entender como e quando a ausência do narrador deixa ao leitor a sensação de incompletude.

Entendemos que, pelo menos dois momentos são significativos quando se trata da ausência da voz filosófica do narrador. O Primeiro deles, do qual antecipadamente já começamos a tratar, diz respeito a Tomas...

\footnotetext{
${ }^{9}$ No filme, esses conflitos são menos existenciais, do modo distinto de como se acentuam no romance, são provocados pela pulsão sexual incontrolável do sedutor que se mostra sempre apto a novas aventuras.

${ }^{10}$ Foucault começa a discutir a sexualidade como prática de si a partir do volume I da História da sexualidade e aprimora essa discussão com A Hermenêutica do sujeito.
} 
Como dissemos, o romance prepara a entrada de Tomas, existe um porquê de sua presença ali, ele nasce à luz das reflexões empreendidas pelo narrador e, ainda que suas ações não sejam controladas autoritariamente pelo narrador-autor, é produto dessas reflexões e transita pela narrativa carregando consigo os fundamentos do pensar que o coloca em cena. Ao contrário disso, o filme se inicia com Tomas centralizando o primeiro quadro. Em seguida ao anúncio do narrador que situa brevemente o lugar, a época e a personagem, damo-nos conta da presença em cena dos primeiros gestos e das primeiras falas de Tomas, quando num diálogo com uma colega de trabalho diz: Tire a roupa./O quê?/Eu disse para tirar a roupa. /Mas você viu tudo ontem à noite. /Preciso verificar uma coisa/Só três segundos. Na sequência ao diálogo, surge a voz do narrador a qual cumpre a função de dizer que a mulher que melhor o entendia era Sabina. Tão logo o narrador conclui sua apresentação, deparamo-nos com Tomas deitado na cama com Sabina.

Vemos então que numa abordagem direta pautada na voz da personagem e utilizando-se da imagem como recurso expressivo, o diretor dispensa as reflexões das quais Tomas emerge no livro, ao mesmo tempo em que as subverte. Nesse quadro, as cenas, as palavras pronunciadas por meio do discurso direto livre e a intervenção do narrador, fazem Tomas solidificar-se na consciência do espectador essencialmente como um conquistador. Ao desprender o protagonista das concepções de Nietzsche e de Parmênides, Kaufman nos apresenta um leve e adorável sedutor que, embora esteja pautado na criação kunderiana, é um outro sedutor, o qual se mostra com outras características e outras funções dentro da obra e diante do espectador.

Em alguns momentos do filme, Tomas surpreende o espectador com algumas frases empreendidas pela voz filosófica do narrador do romance, o que ocorre, por exemplo, nesse diálogo quando fala a Sabina a respeito de sua relação com Tereza:

Você acha que estou fazendo uma grande bobagem. Como posso saber?...Se eu tivesse duas vidas, em uma, eu a convidaria a ficar em casa e na segunda, eu a chutaria para fora,... Aí eu faria a comparação para saber o melhor a ser feito. Mas só vivemos uma vez. A vida é tão leve! É como um contorno que nunca 
podemos... preencher, corrigir...para melhorá-lo é assustador.

As reflexões filosóficas do narrador sobre o Eterno Retorno e sobre o peso e a leveza em Parmênides estão aqui perfeitamente identificadas na voz da própria personagem, contudo tais palavras e frases não dão conta da profundidade necessária - nem parece ser esta a intenção aqui - para levar o espectador a estabelecer outras relações dentro e fora da obra para entender e principalmente refletir sobre o que é dito. Essas palavras são expressas com certa reverência, mas não se detém sobre elas, o filme evolui novamente para a cena seguinte e aquilo que de certa forma, no romance, se constitui em fundamento da personagem, aqui se transforma em recurso que confere ao sedutor certo grau de requinte e erudição, tornando-o por certo mais atraente. A ausência de uma voz filosófica que reflita sobre o que é expresso em palavras, aliada ao ritmo rápido dos acontecimentos - os quais aqui, dentro de uma perspectiva linear e não cíclica -, que só ocorrem uma vez, faz o dito perder o sentido metafóricoreflexivo e se transformar em uma espécie de retórica que contribui para sobressair em Tomas a figura do autêntico e irresistível sedutor delineado pelo imaginário popular com mais precisão a partir do século XVII ${ }^{11}$.

A faceta central de Tomas enquanto grande sedutor pode ser observada também, e principalmente, na relação dele com Tereza e Sabina. É certo que, mesmo com a ausência do narrador, Tereza e Sabina se apresentam como dois pólos distintos, onde a leveza de Sabina se contrapõe ao peso de Tereza, mas apesar de vermos Tomas transitando inquieto no meio desse triângulo amoroso e, paralelamente

\footnotetext{
${ }^{11}$ É fato que a obra de Kundera traz como um dos fundamentos primeiros de análise a figura libertina, que em certo sentido se aproxima da figura donjuanesca apresentada ao público pela peça espanhola do século XVII El burlador de Sevilla y covidado de piedra de autoria do Frei Gabriel Telles que escrevia sob o pseudônimo de Tirso de Molina. Contudo, é visível que os sedutores kunderianos apresentam características que os coloca numa perspectiva diferenciada tanto do conquistador espanhol, quanto da abordagem filmográfica, pois enquanto o don Juan de Kaufman prima pela política do corpo, pela pulsão sexual, os de Kundera fazem do sexo uma prática de si, um meio de buscar a si mesmo na crise identitária própria dos Paradoxos terminais do mundo moderno. Há que se observar que em certos momentos do filme, fica evidente a impossibilidade de se abstrair completamente da voz filosófica do narrador.
} 
a este, buscando novas aventuras, conseguimos perceber na existência de Tomas, certo desconforto e inconformidades que emanam de si mesmo na vivência de suas relações amorosas. Contudo, em vez de conduzir a uma reflexão existencial acerca da personagem, tais sensações, mais uma vez lhe conferem um ar de mistério e distanciamento, quase que erudito, já que ao espectador é impossível extrapolar essa compreensão, visto que se não existe nenhum elemento no filme que nos permita adentrá-lo com maior profundidade, a rapidez conferida pelo tempo dos acontecimentos leva o espectador para a cena seguinte e mina assim qualquer gesto filosófico que se pretenda ter diante dos acontecimentos.

Se o ritmo imposto pelo desenrolar dos acontecimentos faz com que o espectador se prenda mais aos fatos do que a uma compreensão deles, a inexistência do narrador contribui para isso ao impedi-lo de elaborar uma reflexão mais sistematizada sobre o ser e o existir da personagem no decorrer do filme. Qualquer compreensão que se queira da obra de Kaufman não pode ser adquirida passo a passo por meio de relações estabelecidas no ir e vir e no entrelaçar das reflexões tecidas pelo narrador, o sentido só pode ser depreendido como um todo da trama. É dessa maneira que a opção narrativa adotada por Kaufman insere o espectador numa envolvente história de amor rodeada por conflitos e incertezas alimentados pela instabilidade emocional de Tereza e as aventuras eróticas de Tomas. História de amor essa que evolui para um quase final feliz, não fosse a morte de Tereza e Tomas. A opção narrativa que subtrai a voz filosófica do narradora faz com que Tomas deixe de ser um ego experimental nos moldes kunderianos, aqueles que testa as possibilidades humanas, e se permita unicamente à leveza do Ser. A tal ponto que o filme bem que poderia se chamar simplesmente a leveza do ser, já que o insustentável, atributo da voz filosófica do narrador, está para além dele.

Após Tomas, entendemos, como o segundo momento, a ausência do narrador filosófico o qual se torna mais evidente e deixa o espectadorleitor com uma sensação de falta, isso diz respeito à personagem Franz, ao seu relacionamento com Sabina e a sua relação com a 'Grande História'.

No segundo triângulo amoroso composto por Tomas, Sabina e Franz, o narrador-autor se insere com a sua voz reflexiva e, a partir das ações dessas personagens, constrói um quadro representativo do indivíduo dentro da história. Nesse momento, o romance kunderiano coloca no centro do pensar filosófico a seguinte proposição: a história factual é única, mas o modo de vivê-la, de experienciar os fatos é 
próprio e particular de cada Ser. Assim como o primeiro que tem o peso representado na figura de Tereza, esse segundo triângulo amoroso transfere para Franz tal característica. Se Sabina foi o equilíbrio de Tomas para suportar a complexidade do romance com Tereza, aqui é Sabina que busca o equilíbrio entre a leveza de Tomas e o peso de Franz.

Quando no filme, o cineasta abre mão da figura do narrador que pensa, necessariamente dá outro sentido para esse segundo triângulo amoroso. Nessa relação, ainda que seja uma das poucas personagens que assuma uma perspectiva mais reflexiva dentro da obra, Sabina se torna, em essência, uma mulher livre, aberta às diversidades da vida, em se tratando do amor, é desprendida de qualquer tipo de princípio moralista, ela parece encarnar os valores propagados pelos movimentos feministas dos anos 60 - especialmente aqueles voltados para a liberdade sexual que propriamente se configura no ser que carrega consigo os problemas existenciais dentro da 'Grande História'.

Ainda que muito do comportamento de Sabina na composição cinematográfica - seja pela manutenção do chapéu coco, pelo receio de se prender a um lugar ou a uma pessoa - nos permita afirmar ser ela a personagem que mais se aproxima da análise histórico filosófica do indivíduo, que cada vez mais perde suas referências num mundo que caminha para a fragmentação dos seres e dos princípios modernos, revelando uma crise identitária própria do tempo e do lugar de onde fala seu criador, aqui, uma combinação da subtração da voz filosófica do narrador com a expressividade das imagens e o encaminhamento, salvo em poucos momentos, linear e ininterrupto do enredo, conduz o espectador a outra direção, aquela que apresentará Sabina como a mulher que melhor entende Tomas, sua amante. Dessa maneira, em relação à Tereza, num primeiro momento, Sabina se configura como o centro desencadeador da insegurança e dos ciúmes de Tereza e mais tarde desenvolve também com ela uma relação velada que oscila entre a amizade e a atração ${ }^{12}$.

\footnotetext{
12 Dentro dessa perspectiva de liberdade que envolve Sabina, a seção de fotos com Tereza no ateliê em Genebra torna-se uma das cenas mais expressivas não só do filme, mas do cinema. A despretensão filosófica talvez seja o que possibilite aqui a grandiosidade dessa cena, esse momento da criação de Kaufman diz por si só, seja pela beleza, seja pela delicadeza, seja pela aparente ausência de intenções. Contraditoriamente, esse momento só é o que é, porque traz consigo a capacidade de ser mais estético do que semântico, o que nos parece despontar como pretensão primeira de seu autor.
} 
Se no filme esse segundo triângulo amoroso faz sobressair a figura de Sabina, no livro, ela solidifica-se enquanto ego experimental que vive a dualidade do peso e da leveza, resultantes das ideias de Ser e Não-Ser de Parmênides. Entretanto, é importante dizer que a experiência de Sabina, que permite a inserção do pensamento do narrador-autor, só se constitui na relação com Franz.

$\mathrm{Na}$ terceira parte do livro intitulada As palavras incompreendidas, temse acesso ao valor das palavras para Sabina e para Franz, nessa passagem o narrador empreende uma reflexão, entre outras, acerca do que é mulher, verdade, luz e escuridão. No tecer das proposições revelam-se as contradições entre o valor atribuído por Sabina e Franz às mesmas palavras. É assim, então que no filme a narrativa em torno de Franz tornase um dos momentos onde mais se evidencia, para o espectador-leitor, a ausência da voz filosófica do narrador. Ao contrário do filme, no romance, a personagem de Franz tem valor significativo como elemento semântico da narrativa, e existe também, e principalmente, enquanto produto das reflexões empreendidas pela voz filosófica.

Dentro de uma concepção reflexiva, Franz é, sem dúvida, uma personagem central do texto original e que no filme, exatamente pela ausência da voz do narrador, torna-se uma personagem quase figurativa. No reduzido espaço que lhe é destinado, Franz apresenta-se mais como uma nova aventura amorosa de Sabina, que propriamente uma personagem sobre a qual nos debruçamos para compreender as contradições e incertezas do homem que caminha para o fim do 'breve século XX' (HOBSBAWM, 1995).

\section{Conclusão}

A ausência do narrador - não um narrador qualquer e sim o narrador kunderiano com suas especificidades, aquele que leva ao leitor a certo grau de cumplicidade na construção e experimentação do fazer artístico - é o elemento que, na nossa concepção, faz com que o espectador-leitor tenha a sensação de incompletude quando se vê diante do filme. Acreditamos, e aqui procuramos trazer estas considerações, que isso ocorre porque o narrador composto pela tríade, narrador-autor-personagem, faz que a obra desse escritor seja inseparável desta sua criação estética. 
Basta ver aqui os dois comentários citados no início desse trabalho, para darmos conta de que os leitores os quais revelam tal insatisfação quanto ao filme pertencem ao grupo dos que já leram o livro. Um deles chega a afirmar que não entrou de inocente, pois "já estava contaminado pela riqueza do texto de Kundera." Tomas desvinculado da ideia do Eterno Retorno ou das contradições entre o Ser e Não-Ser de Parmênides e a relativização de Franz no filme são sem dúvida os dois momentos cruciais dessa ausência, pois além da significação delas no romance, essas duas personagens são fundadas no pensar filosófico da voz narrativa e são elas, portanto, que mais fazem o espectador-leitor se ressentir da falta do narrador na produção cinematográfica.

Quando audaciosamente - dizemos audaciosamente porque, reiteramos a afirmativa de ser difícil supor que o diretor do filme estivesse alheio à força do narrador no texto original - Kaufman por um lado corre o risco da incompreensão dos leitores, mas por outro, estabelece um caráter autônomo para sua obra, embora seja uma adaptação do romance de Kundera, a produção de Kaufman configura-se como outra obra, que parte do original, mas não tem nenhum compromisso com ele, o que apresenta nas telas do cinema não é $A$ Insustentável Leveza do Ser de Kundera, mas sim uma releitura que lhe é própria e a qual faz nascer uma outra obra, o filme A Insustentável Leveza do Ser.

\section{REFERÊNCIAS}

BARROSO, Wilton. Elementos para uma Epistemologia do Romance. Colóquio: Filosofia e literatura. São Leopoldo: Usininos, 2003.

BARROSO, Wilton. A voz filosófica do narrador kunderiano. XI Congresso Internacional da Abralic: Tessituras, Interações, Convergências. São Paulo: USP, 2008.

BAZIN, A. O cinema: ensaios. Trad. Eloísa de A. Ribeiro. Aão Paulo: Brasiliense, 1991.

BENJAMIN, Walter. O narrador: considerações sobre a obra de Nikolai Leskov In: Magia e técnica, arte e política. Ensaios sobre literatura e história da cultura. Obras Escolhidas. Trad. Sérgio Paulo Rouanet. São Paulo: Brasiliense, 1994. 
CASTILHO, Pedro. O uso da língua na episteme moderna ou a lingüística, a literatura e o autor como atitudes contra teológicas. Literatura e outras áreas do conhecimento. Revista Cerrados - publicação do Departamento de Teoria Literária e Literaturas. Org. Sylvia Helena Cyntrão. ano 15, n. 21, Brasília: UNB, 2006, p. 123.

FOUCAULT, Michel. A hermenêutica do sujeito. Trad. Márcio Alves da Fonseca, Salma Tannus Muchail. São Paulo: Martins Fontes, 2006.

HOBSBAWM, Eric J. Era dos Extremos: o breve século XX. Trad. Marcos Santarrita. São Paulo: Companhia das Letras, 1995.

KUNDERA, M. A arte do romance. Trad. Teresa Bulhões C. da Fonseca e Vera Mourão. Rio de Janeiro: Nova fronteira, 1988.

A insustentável leveza do Ser.Trad. Teresa Bulhões C. da Fonseca. Direitos de edição da obra em Língua Portuguesa da Ed. Nova Fronteira, cedidos à Ed. Record de Serviços de Imprensa S.A. Rio de Janeiro: Record, 1995.

A brincadeira. Trad. Teresa. Bulhões C. da Fonseca e Ana Lúcia Moojen Andrada. Rio de Janeiro: Nova fronteira, 1986.

. A imortalidade. Trad. Teresa Bulhões C. da Fonseca e Anna Lúcia Moojen Andrada. Rio de Janeiro: Nova Fronteira, 1990.

LUKÁCS, Georg. A teoria do romance: um ensaio histórico-filosófico sobre as formas da grande épica. Trad. José Marcos Mariani de Macedo. São Paulo: Duas Cidades/Ed. 34, 2000.

MOLINA, Tirso de. O burlador de Sevilha e o convidado de Pedra. Trad. Alex Cojorian. Brasília: Círculo de Brasília, 2004.

\section{REFERÊRENCIA FILMOGRÁFICA}

A Insustentável Leveza do Ser (Original: The Unbearable Lightness of Being). Direção: Philip Kaufman, Roteiro: Jean-Claude e Produção: Saul Zaentz. EUA, 1988. 